\title{
Direito humano à vida: a objeção médica e a interrupção de gravidez
}

\author{
Human right to life: medical objection and interruption of pregnancy
}

REGiANE NisTLER

Universidade Estácio de Sá/RJ (UNESA).

Marco Augusto Ghisi Machado

Universidade do Vale do Itajaí/SC (UNIVALI).

RESUMo Este estudo objetivou especificamente estudar o direito à vida em relação à objeção médica e à possibilidade de a mulher interromper a própria gravidez, visto sua relevância jurídico-penal e o temor de consequências legais e sociais que recaem sobre o profissional de saúde objetor. Foi estabelecida a seguinte problemática: o que é considerado em situações que se identifica a "objeção médica X interrupção de gravidez" em relação ao bem maior que é a vida? Para a pesquisa, foram levantadas as seguintes hipóteses: a) Em relação à objeção de consciência médica, no procedimento de interrupção da gravidez, o médico pode opor-se a um pedido de aborto; b) Objeções só podem ser motivadas por crenças particulares, como no caso das crenças religiosas; c) $\mathrm{O}$ médico não pode julgar que a narrativa do estupro é inverídica, uma vez que há uma "presunção de veracidade na palavra da mulher"; d) Ao alegar a objeção de consciência, o médico deve solicitar autorização para não cumprir a sua obrigação. A mulher deve ser atendida por outro médico; e) Orientações técnicas do Ministério da Saúde não reconhecem o direito à objeção de consciência, quando existe um risco de morte, quando não há outro médico ou quando a falta de atenção médica prejudica as mulheres, mas os casos recentes revelam a não-adesão ao critério normativo. O método de abordagem utilizado é o dedutivo.

Palavras-chave: Aborto legal. Direito à vida. Objeção de consciência.

ABSTRACT This study specifically aimed to study the right to life in relation to medical
objection and the possibility for women to terminate their own pregnancy, given its legal-
penal relevance and the fear of legal and social consequences that fall on the objecting
health professional. The following problem was established: what is considered in situa-
tions where the "medical objection X termination of pregnancy" is identified in relation to
the greater good that is life? For the research, the following hypotheses were raised: a) In
relation to the objection of medical conscience, in the procedure of termination of preg- 
nancy, the doctor may, oppose an abortion request; b) Objections can only be motivated by particular beliefs, as in the case of religious beliefs; c) The doctor cannot judge that the rape narrative is untrue, since there is a "presumption of veracity in the woman's word"; d) When claiming the conscientious objection, the doctor must request authorization not to fulfill his obligation. The woman must be seen by another doctor; e) Technical guidelines from the Ministry of Health do not recognize the right to conscientious objection, when there is a risk of death, when there is no other doctor or when the lack of medical attention harms women, but recent cases reveal non-adherence normative criteria. The approach method used is the deductive one.

KeYwORDS: Legal ABORTION. Right to Life. OBJeCtion OF CONSCIENCE.

\section{INTRODUÇÃo}

A atuação médica exige inúmeras responsabilidades, que percorrem entre científicas, técnicas, morais, éticas, sociais, civis, criminais e disciplinares, todas unificadas pelo conceito de responsabilidade médica, compreendidas como a obrigação de arcar com as consequências de um comportamento, um fato ou um ato médico, aceito e executado por um profissional médico livremente. Esse conjunto de ideias é presidido pela consciência individual, ou seja, o conhecimento íntimo do bem a se alcançar e o mal a evitar, isto é, o conhecimento exato e reflexivo dos assuntos e conteúdos relacionados à saúde.

Por conseguinte, entende-se por objeção de consciência, na medicina, a recusa de executar um procedimento médico direta ou indiretamente, cooperar na sua implementação, mesmo que tal procedimento tenha sido aprovado pelas normas legais, por motivos morais, éticos ou religiosos. Essa objeção pode ocorrer nos casos de interrupção da gravidez, quando tais procedimentos são legalmente autorizados.

Mas o médico, seja qual for a sua especialidade, pode ser confrontado com situações em que surge um conflito entre o dever de prestar assistência médica e a recusa do paciente em receber tal assistência, como no caso dos pacientes Testemunhas de Jeová, que se recusam a receber transfusão de sangue, colocando em risco a própria vida. Nesse caso, o dilema do médico é prestar a assistência contra a vontade do paciente e salvar sua vida ou respeitar sua vontade e deixá-lo morrer. Há fatores complicadores, como o caso de pacientes incapazes ou menores de idade.

Ainda, uma das situações mais delicadas quanto à atuação do médico sem dúvida é diante da possibilidade de a mulher interromper sua gravidez, como será tratado neste estudo. Para tanto, o trabalho é dividido em três seções. A primeira busca abordar o direito à vida, enquanto a segunda visa estudar o regime jurídico do médico e a objeção da consciência na atuação médica, enquanto a terceira seção mencionará a possibilidade de interrupção da gravidez pela mulher, momento no qual o estudo, ainda que brevemente, busca analisar a situação objeção da consciência médica $\mathrm{X}$ interrupção da gravidez, tendo como norte $\mathrm{e}$ pano de fundo o maior bem: a vida, enquanto direito humano e fundamental. 


\title{
O DIREITO HUMANO À VIDA
}

Discorrer sobre o direito humano e fundamental à vida é tarefa das mais complexas, pois para falar sobre ele, é necessário adentrar um campo ainda mais nebuloso, qual seja, conceituar o que é VIDA.

A dificuldade reside no grande número de conceitos encontrados, a depender do ponto de vista abordado, por exemplo, o religioso, o biológico, o moral, o filosófico, o jurídico, e, ainda, em qual momento histórico está inserido.

A palavra vida pode assim ser definida:

\begin{abstract}
Vida é o estado ou condição dos organismos capazes de desempenhar transformações complexas de moléculas orgânicas (essenciais a atividades funcionais como metabolismo, crescimento e reprodução). Esses seres evoluem por seleção natural e produzem cópias mais ou menos idênticas de si mesmos, transmitindo às gerações seguintes as instruções necessárias para que elas próprias se repliquem ou reproduzam (Grande Enciclopédia Barsa. Barsa Planeta Internacional LTDA: São Paulo, v. 14, 2005, p. 371).
\end{abstract}

Platão (2001) considera o início da vida o momento em que alma e corpo se unem um ao outro, e a morte seria a separação da alma e do corpo na vida terrena. Já Aristóteles entendia como fase inicial da vida quando o feto realizasse os primeiros movimentos. Sua teoria foi bastante difundida por São Tomás de Aquino e adotada pela Igreja Católica no período Escolástico.

No entanto, foi a partir do papado de Pio IX, em 1869, que o momento da fecundação passou a ser adotado como o princípio da vida, ou seja, o encontro do óvulo com o espermatozoide. Essa teoria ainda hoje é sustentada pela Igreja Católica (FALCÃO, 2012).

Da mesma forma que o catolicismo adota a concepção como início da vida, diversas religiões também têm suas teorias. O judaísmo afirma que a vida inicia a partir do $40^{\circ}$. dia da fecundação. No islamismo, o marco inicial da vida seria o $120^{\circ}$. dia posterior à fecundação, quando Alá sopraria a alma no corpo do feto. Já o hinduísmo parte do pressuposto que a vida começa na fecundação quando a alma e a matéria se encontram, entendimento parecido com o adotado pelo catolicismo (FALCÃO, 2012).

Ao longo da História surgiram vários conceitos filosóficos e religiosos tentando delimitar o início da vida, todavia é na seara científica que os juristas têm buscado encontrar uma resposta para tão debatida questão. Entretanto, nem mesmo a ciência conseguiu encontrar uma resposta única acerca do princípio da vida. Nesse contexto, diferentes teorias e estudos a respeito da origem da vida humana surgiram. Entre elas podemos destacar a teoria da concepção, nidação, implementação do sistema nervoso, entre outros (PUSSI, 2005, p. 191-197)

A teoria da concepção ou genética defende a existência da vida humana desde o momento da concepção. Esta é adotada pela Igreja Católica e é também acolhida pelo Direito Brasileiro. Nesse sentido, é o que dispõe o Código Civil de 2002 em seu artigo $2^{\circ}$.: "A personalidade civil da pessoa começa do nascimento com vida; mas a lei põe a salvo, desde a concepção, os direitos do nascituro". Para essa corrente o embrião humano desde a sua 
concepção já é considerado uma pessoa humana e, portanto, merece a proteção jurídica (PUSSI, 2005, p. 191-197).

Na opinião de William Artur Pussi (2005, p. 191-197) entre 24 e 36 horas após a fecundação surge a primeira célula individualizada (zigoto ou blastócito), a qual começa a dividir-se, dando origem ao embrião. E, somente após seis semanas, o embrião passará a ser chamado de feto. No entanto, é incontestável que o embrião já traz consigo toda uma informação hereditária, um código genético distinto e único (o genoma) que se transmite às demais células.

Nas palavras de Pussi (2005, p. 1991-1997):

Uma coisa é indiscutível: desde o zigoto, o que se tem é vida; vida diferente do espermatozoide e do óvulo; vida diferente da do pai e da mãe, mas vida humana, se pai e mãe são humanos. Pré-embrionária a início, embrionária, após, mas vida humana. Em suma desde a concepção a vida humana nascente a ser tutelada.

A teoria da nidação exige a fixação do óvulo no útero como marco inicial da vida, pois é a partir desse momento que o embrião, no útero materno, encontra as condições adequadas para o seu desenvolvimento.

Outra tese desenvolvida é a genético desenvolvimentista, que considera que a formação do ser humano se dá com o desenvolvimento de várias etapas sucessivas, como o pré-embrião, embrião e por fim a formação do feto. Essa corrente defende que o embrião já pode ser considerado como pessoa humana e, por consequência, ter seus direitos tutelados. Essa teoria é adotada na legislação de vários países europeus, onde se autoriza a manipulação de pré-embriões para estudos ou até mesmo a sua inutilização (FALCÃO, 2012).

A teoria neurológica parte do pressuposto que a morte é declarada com o fim das ondas cerebrais, como consequência lógica, o princípio da vida seria o momento em que o embrião passasse a ter os primeiros sinais de células nervosas com atividade. Já a teoria ecológica afirma que a vida se inicia no instante em que a vida, fora do útero materno, seja viável para o feto. E esse momento ocorre quando seus pulmões se encontram prontos para realizar suas funções, o que ocorre por volta da $24^{\mathrm{a}}$. e 25 . semanas de gravidez (FALCÃO, 2012).

A diversidade de teorias existentes demonstra a importância do tema. Sendo o direito à vida um dos pressupostos básicos de todos os demais direitos e liberdades do ser humano, é imprescindível saber o marco inicial, pois é a partir desse instante que a vida encontrará guarida no texto constitucional.

A Constituição Brasileira enumera, em seu artigo $5^{\circ}$., o direito à vida, que é seguido da liberdade, igualdade, segurança e propriedade (BRASIL, 1988).

É o mais elementar de todos os direitos, sendo visto como verdadeiro pré-requisito para a existência dos demais direitos. A vida é o direito humano mais sagrado, e o homem, pelo simples fato de estar vivo, é dotado de grande valor.

Para Mendes e Branco (2012, p. 289) "o direito à vida é a premissa dos direitos proclamados pelo constituinte; não faria sentido declarar qualquer outro se, antes, não fosse assegurado o próprio direito de estar vivo para usufruí-lo".

Quanto à sua abrangência, o direito à vida apresenta duas facetas: Em primeiro lugar, encontra-se o direito de permanecer vivo; e em segundo lugar, o direito a uma vida digna. 
Assim, cabe ao Estado assegurar a todos o direito de permanecer vivo, seja por meio de políticas de segurança pública, proibição da justiça privada e por parte do próprio Estado o respeito à vida de seus cidadãos.

Para José Afonso da Silva (2008, p. 198), o direito de estar vivo consiste em "lutar pelo viver, de defender a própria vida, de permanecer vivo. É o direito de não ter interrompido o processo vital senão pela morte espontânea e inevitável". É decorrência do direito à vida que o direito penal pune todas as formas de interrupção violenta da vida e mais, sendo um direito e não uma liberdade, não cabe a alternativa pelo suicídio. Deve a vida ser protegida até mesmo contra a vontade do titular do direito.

Para Jacques Robert (1980, p. 234):

O respeito à vida humana é a um tempo uma das maiores ideias de nossa civilização e o primeiro princípio da moral médica. É nele que repousa a condenação do aborto, do erro ou da imprudência terapêutica, a não-aceitação do suicídio. Ninguém terá o direito de dispor da própria vida, a fortiori da de outrem, e, até o presente, o feto é considerado um ser humano (SILVA, 2008, p. 198).

É papel do Estado, ainda, assegurar um padrão mínimo de vida, compatível com a dignidade humana. Nesse âmbito, inclui-se o direito à alimentação adequada, à moradia (art. 5., inc. XXIII), ao vestuário, à saúde (art. 196), à educação (art. 205), à cultura (art. 215) e ao lazer (art. 217) (TAVARES, 2009, p. 543).

$\mathrm{O}$ direito à vida como princípio constitucional guarda estreita relação com o direito a uma existência digna e humana, ratificado pelo artigo $1^{\circ}$., inciso III da CF/88.

A corrente constitucionalista atual tem defendido que o direito à vida atinge um patamar mais elevado que o puro direito de estar vivo, predominando entre os estudiosos a teoria do direito à vida com dignidade. Sendo assim, o princípio da dignidade da pessoa humana deve ser entendido como o alicerce que salvaguarda as características inerentes a todo ser humano, devendo sobressair o respeito a uma vida decente que garanta condições mínimas para a sustentabilidade, autodesenvolvimento, e, acima de tudo, existência digna.

\section{O REGIME JURÍDICO DO MÉDICO E SUA ATUAÇÃo DIANTE DA OBJEÇÃo DE CONSCIÊNCIA}

O exercício da Medicina implica a intervenção direta e muitas vezes agressiva do médico na integridade física e mental de seus pacientes, com o objetivo de melhorar o estado deles, porém correndo o risco de lesioná-los de forma grave ou irreparável. O avanço da Medicina e a consequente e maciça utilização das novas tecnologias em muito auxiliaram os procedimentos médicos, mas também ampliaram os riscos que sempre acompanharam essa ciência em todas as épocas da História (GARCIA, 2011, p. 521).

Os médicos, apresentados a essas novas alternativas, procuram intervir em casos antes considerados incuráveis e sem opção de tratamento. Para empregar as novas técnicas, porém, é necessário treinamento sofisticado e dispendioso, não acessível a todos os profissionais. Esses fatores acarretam maior probabilidade de criação de situações arriscadas por aqueles que não conseguem manejá-las corretamente (GARCIA, 2011, p. 521).

Nessa perspectiva, cumpre salientar que a Medicina e o Direito são dois ramos de estudo imprescindíveis para a sociedade e que, notoriamente, vêm evoluindo com uma velocidade extremamente rápida. Nos últimos tempos, têm vivenciado alguns atritos, o 
que contribuiu para a normatização da atividade médica. Vale frisar que esses conflitos fundam-se na resistência de o médico aceitar ser punido pelos erros que venha a cometer no exercício de suas atividades profissionais.

Tal premissa, de acordo com Pacheco (PACHECO, 1991, p. 29), foi oficializada pela Academia de Medicina de Paris, em 1829, que defendia que a responsabilidade do médico era moral e de consciência, logo não era necessária qualquer represália jurídica. Sobre essa matéria o autor assinala que:

[...] a Medicina sofreu um extraordinário e vertiginoso progresso. O médico, que antes sempre tivera como guias sua consciência e uma tradição milenar, tem hoje, como cidadão o dever e a necessidade de conciliar esse pensamento e o interesse profissional com as múltiplas leis e exigências que regulam o convívio social (PACHECO, 1991, p. 31).

Por isso, observa-se que o médico deve responder pelas faltas legais ou morais cometidas no exercício de sua atividade, em conformidade com as disposições legais que regem a sua conduta. Além disso, importa salientar que, a sociedade contemporânea também está mais informada sobre os seus direitos, inclusive como pacientes, ampliando a responsabilidade do médico, que deve estar ciente de que responderá por todos os seus atos.

Além disso, convém salientar a fragilidade emocional do paciente quando recorre ao médico na busca de um único objetivo - curar-se.

[...] é uma criatura absolutamente indefesa, atemorizada, aterrorizada, e a sua expectativa é sempre a mais periclitante possível, ou seja, quando chega na busca da prestação do serviço médico, ele o faz debaixo de tal pressão, que o tratamento alcança não só a patologia da qual eventualmente possa estar sofrendo, mas também a própria situação psíquica, diante da falta de riqueza do conhecimento extraordinário que está por trás da Medicina, "essa velha senhora" (DIREITO, 2005, p. 188).

Nesse sentido, observa-se que a confiança para o consentimento do ato médico é praticamente imediata, cabendo ao profissional de Medicina o dever jurídico de informar ao paciente sobre o procedimento de forma ética, objetiva e simples, para que possa compreendê-lo e consentir com a realização do procedimento de maneira consciente (GARCIA, 2011, p. 533).

Ressalta-se que, diante dessa nova perspectiva de responsabilização do médico pelos seus procedimentos, o Conselho Federal de Medicina incluiu, em seu Código de Ética Médica ${ }^{1}$

Segundo os dispositivos do capítulo V do referido Código, o médico não tem o direito de:

"Art. 31. Desrespeitar o direito do paciente ou de seu representante legal de decidir livremente sobre a execução de práticas diagnósticas ou terapêuticas, salvo em caso de iminente risco de morte.

Art. 32. Deixar de usar todos os meios disponíveis de diagnóstico e tratamento, cientificamente reconhecidos e a seu alcance, em favor do paciente.

Art. 33. Deixar de atender paciente que procure seus cuidados profissionais em casos de urgência ou emergência, quando não haja outro médico ou serviço médico em condições de fazê-lo.

Art. 34. Deixar de informar ao paciente o diagnóstico, o prognóstico, os riscos e os objetivos do tratamento, salvo quando a comunicação direta possa lhe provocar dano, devendo, nesse caso, fazer a comunicação a seu representante legal.

Art. 35. Exagerar a gravidade do diagnóstico ou do prognóstico, complicar a terapêutica ou exceder- se no número de visitas, consultas ou quaisquer outros procedimentos médicos.

Art. 36. Abandonar paciente sob seus cuidados.

$\S 1^{\circ}$ Ocorrendo fatos que, a seu critério, prejudiquem o bom relacionamento com o paciente ou o pleno 
(2010), normas de comportamento que podem estabelecer limites ao risco permitido no ato médico.

Segundo Garcia, tais normas referem-se:

[...] ao prescrever a obrigatoriedade de informação adequada aos pacientes (arts. 40, 46, 59 e 60), ao recomendar o respeito a capacidade de decisão do paciente (arts. 46 e 48), ao recomendar a atualização técnica constante do profissional (arts. 5) e ao determinar a proibição de práticas danosas ao interesse do paciente (arts. 29, 42, 50, 52 e outros), além de estabelecer o risco tolerado no ato médico (GARCIA, 2011, p. 542).

Todavia, Garcia (2011, p. 542-543) alerta que o Código de Ética Médica (2010) consiste em um conjunto de normas, mas de cunho ético pouco específicas e, por conseguinte, de difícil aplicação em casos concretos, associadas à disposições inócuas. Assim, observa-se que, embora o órgão que normatiza a profissão do médico no Brasil ainda não tenha se colocado de maneira mais significativa no que diz respeito ao estabelecimento de normas objetivas que orientem a postura médica, acrescidas das devidas sanções que implicam o não cumprimento delas, o Direito vem estudando os casos concretos e assinalando a sua participação na penalização de condutas médicas que causem dano ao paciente.

Ainda, é importante considerar claramente o que se entende por objeção de consciência médica. Razão pela qual Priego Muñoz define como sendo o desacordo por parte dos profissionais de saúde em realizar, por questões de cunho ético e/ou religioso, determinados atos que estão legalmente autorizados. Essa posição é um ato de grande dignidade moral quando as razões dadas por esses profissionais são sérias, constantes e sinceras, e se referem a questões sérias e fundamentais.

desempenho profissional, o médico tem o direito de renunciar ao atendimento, desde que comunique previamente ao paciente ou a seu representante legal, assegurando-se da continuidade dos cuidados e fornecendo todas as informações necessárias ao médico que lhe suceder.

$\S 2^{\circ}$ Salvo por motivo justo, comunicado ao paciente ou aos seus familiares, o médico não abandonará o paciente por ser este portador de moléstia crônica ou incurável e continuará a assisti-lo ainda que para cuidados paliativos.

Art. 37. Prescrever tratamento ou outros procedimentos sem exame direto do paciente, salvo em casos de urgência ou emergência e impossibilidade comprovada de realizá-lo, devendo, nessas circunstâncias, fazê-lo imediatamente após cessar o impedimento.

Parágrafo único. $\mathrm{O}$ atendimento médico a distância, nos moldes da telemedicina ou de outro método, dar-se-á sob regulamentação do Conselho Federal de Medicina.

Art. 38. Desrespeitar o pudor de qualquer pessoa sob seus cuidados profissionais.

Art. 39. Opor-se à realização de junta médica ou segunda opinião solicitada pelo paciente ou por seu representante legal.

Art. 40. Aproveitar-se de situações decorrentes da relação médico paciente para obter vantagem física, emocional, financeira ou de qualquer outra natureza.

Art. 41. Abreviar a vida do paciente, ainda que a pedido deste ou de seu representante legal. Parágrafo único. Nos casos de doença incurável e terminal, deve o médico oferecer todos os cuidados paliativos disponíveis sem empreender ações diagnósticas ou terapêuticas inúteis ou obstinadas, levando sempre em consideração a vontade expressa do paciente ou, na sua impossibilidade, a de seu representante legal.

Art. 42. Desrespeitar o direito do paciente de decidir livremente sobre método contraceptivo, devendo sempre esclarecê-lo sobre indicação, segurança, reversibilidade e risco de cada método." 
Dessa forma, pode-se dizer que a objeção de consciência médica diz respeito à rejeição médica a ações e não a pessoas.

Para entender esse cenário, é necessário conhecer a evolução da relação médico-paciente. No início, a medicina materializou seu princípio de beneficência com um modelo paternalista, onde o médico era visto como um pai que se tornava a referência de autoridade sobre o filho, impunha seu critério de prática, ignorando as considerações do paciente. Hoje, o regime paternalista deu lugar a um regime contratualista, em que médico e paciente não são mais pai e filho, respectivamente, mas partes contratantes. Sendo assim, deve haver um equilíbrio entre eles e tanto o consentimento quanto a autonomia serão os alicerces da relação médico-paciente. O médico não impõe os seus critérios e a realização de procedimentos médicos é o resultado de um consenso com o paciente. Isso é de grande importância para o assunto em questão aqui, uma vez que o reconhecimento do consenso médico-paciente significa implicitamente uma potencial dissidência, que é propícia para o surgimento da objeção de consciência (GARCIA, 2005).

A objeção de consciência tem uma forte ligação com essa relação, já que há um confronto entre duas consciências a respeito de um bem transcendental a ambos: a vida e seus valores. Aqui, o exercício da objeção de consciência é uma manifestação da autonomia das extremidades do relacionamento: a liberdade de prescrição, no caso da liberdade médica, e a liberdade terapêutica, no caso do paciente (LEE; SOTELO; CASA).

A literatura científica (LEE; SOTELO; CASA) dispõe que a objeção de consciência médica:

1. Sustenta-se na ética médica.

2. Possui um caráter individual, em que imperativo moral interno prevalece sobre qualquer impacto social.

3. Expressa-se a título pessoal, o que torna impossível ser invocada por

4. terceiros.

5. É formalizada publicamente.

A dissidência envolvendo a objeção de consciência, no domínio dos cuidados de saúde, não pode reivindicar a subversão da ordem normativa e fazer da posição dissidente uma regra geral. Em outras palavras, a dissidência decorrente da objeção de consciência é a objeção contra o regulamento contestado, que continua a ser a referência normativa geral (GARCIA, 2005). Razão pela qual um clínico objetor não pode proibir que profissionais não objetores pratiquem o ato que motivou a objeção. Isso significa que o médico pode decidir apenas sobre os seus próprios atos, estando vedado a ele fazer de sua vontade uma regra.

De acordo com o Juramento de Hipócrates, ninguém pode dispor da vida no desenvolvimento de atos biomédicos, de modo que o médico pode ser dispensado de realizar, por exemplo, um aborto, invocando objeção de consciência (GARCÍA FERNÁNDEZ, 2007, p. 26-28). Bonilla Sanchez (2011) diz que com a sua atitude de rejeição, o profissional de saúde, público ou privado, não infringe qualquer dever constitucional ou legal de interromper a gestação, porque não impõe que sua vontade se torne a norma. A objeção de consciência apenas atende a um juramento profissional e a uma obrigação ética, 
sancionada pela lei e regulamentação para proteger e não para frustrar a vida humana em qualquer estágio de desenvolvimento.

No entanto, essa oposição ou discordância não pode ser aplicada de forma indiscriminada. Quando um aborto for necessário, a objeção torna-se inválida, porque o médico não pode abster-se de prestar a assistência médica necessária, sob pena de sua conduta ser caracterizada como crime, como homicídio ou lesão corporal (GARCÍA FERNÁNDEZ, 2007, p. 28). Em relação ao direito brasileiro, por exemplo, há situações em que a interrupção da gravidez é prevista na legislação por acarretar risco iminente à vida da mãe. Dada a situação da saúde pública no país, há momentos em que o médico precisa escolher entre a vida da mãe ou do feto, e a vida da mãe deve prevalecer sobre a do feto. Nesse caso, se não houver outro médico disponível para realizar o procedimento, entende-se que o médico com objeção de consciência em relação ao aborto não pode simplesmente recusar-se a realizar o procedimento, colocando em risco a vida da gestante.

Gómez Rivero (2003) observa que o cenário clássico de objeção de consciência surge do conflito entre quem afirma a objeção e a pessoa afetada pelo exercício, e dá como exemplo a atitude do médico na prática do aborto solicitado, e no caso inverso, em que o médico tem a intenção de praticar um aborto, contra a vontade da mulher, no âmbito de um risco para a sua vida ou em razão de defeitos congênitos que causam ao feto tal sofrimento que, ao ver do professional de saúde, é moralmente inaceitável. A objeção de consciência é levantada contra uma regra de proibição, que consiste na obrigação que o médico possui, teoricamente, de se abster e respeitar a vontade da gestante.

Segundo Rivero (2003), no caso de haver uma discrepância entre a vontade do afetado e quem alega as razões de consciência, tais razões não devem ser ignoradas. Nesse caso, seus limites devem ser ancorados de forma que o atendimento às objeções de consciência de quem se opõe ao ato não impeçam os afetados, por sua vez, de agir em consciência, isto é, de acordo com suas próprias crenças ou princípios éticos, morais ou religiosos. Sobre esse tema específico, ou seja, acerca da objeção de consciência, no que diz respeito ao aborto, muitos países europeus regulamentam o direito de objeção dos profissionais de saúde. Entre esses países, podemos citar a França, Alemanha, Itália, Holanda e Reino Unido (PELAYO, 2011, p. 115-144).

No entanto, a maioria das legislações europeias também garante que quando o Estado não fornece a presença de número suficiente de profissionais para a prática do aborto nos casos previstos pela lei, e há apenas um profissional médico que está habilitado para realizá-lo, este será obrigado a praticá-lo. Nesse caso, os tribunais europeus entendem que a restrição à observação do direito fundamental à objeção de consciência é completamente legítima, devido à necessidade de preservar os direitos fundamentais de terceiros afetados, em particular a saúde e a vida da mulher grávida (GARCIA, 2005).

No caso em que a objeção seja possível, o médico deve fazê-la por escrito, indicando, em primeiro lugar, as razões pelas quais tal prática médica está em conflito com as suas convicções religiosas ou morais mais íntimas e, segundo, o nome do profissional de saúde que se encarregará do paciente, havendo a certeza da existência de tal profissional e da sua experiência para realizar o procedimento e sua disponibilidade de tempo na ocasião necessária (GARCIA, 2005). 
Há também a questão da objeção de consciência do farmacêutico. O caso clássico é o farmacêutico que se recusa, por razões de consciência, a fornecer ou entregar a pílula pós-coito, também chamada de "pílula do dia seguinte". A justificativa para a recusa pode ser: I) profissional, sob a irrelevância ou ineficácia da droga; ou II) ética, por causa do conflito entre os efeitos do medicamento e as crenças morais ou religiosas (BONILLA, 2011), (III) ou científica, por causa de efeitos colaterais mais graves que os benefícios.

A legislação e jurisprudência brasileiras não dizem nada a respeito. Acredita-se que, caso uma negação desse direito já tenha ocorrido, a requerente tenha preferido dirigir-se a outra farmácia, em vez de pleitear seu direito na justiça, tendo em vista que o uso do anticoncepcional emergencial não poderia aguardar por uma decisão judicial, ou perderia sua eficácia. Priego Muñoz, contudo, observa que a objeção de consciência não pode ser usada para recusar o fornecimento de um medicamento prescrito por um médico (MUÑOZ).

No caso específico da interrupção da gravidez, outro ponto que poderia criar dificuldades quando se trata de estabelecer a legitimidade de se recusar à realização de determinado procedimento refere-se à assistência médica após o procedimento cirúrgico que levou à interrupção da gravidez. Gómez Rivero (2003) salienta que não é possível invocar a objeção, uma vez que não afeta mais a manobra abortiva, mas o cuidado e atenção que deve ser oferecida às mulheres que tenham sido submetidas a uma intervenção.

Suarez Bello $(2015$, p. 3) estabelece critérios para determinar quando a objeção de consciência é permitida e quando não é amparada pela lei. Esse critério é ancorado em três elementos: 1) a sinceridade das crenças do objetor; 2) o respeito pelos direitos fundamentais de terceiros; e 3) a inocuidade das consequências, o que resulta em um julgamento da proporcionalidade.

O exercício da objeção de consciência também pode afetar outros direitos legais, como a liberdade individual, especialmente quando o médico aplica tratamento médico contra a vontade do paciente. Conclui-se que, atualmente, a relação médico-paciente é regida pelo princípio da autonomia, tanto o paciente quanto o médico são seres autônomos, com o direito de pensar, refletir e agir de acordo com sua própria vontade e seu livre-arbítrio.

\section{INTERRUPÇÃO DE GRAVIDEZ}

“O termo 'aborto', originário do latim abortus, advindo de aboriri (morrer, perecer), vem sendo empregado para designar a interrupção da gravidez antes de seu termo normal" (DINIZ, 2014, p. 31). Esse assunto gerou e ainda gera intensa polêmica em todo o país face a recente decisão, sob forma cautelar, do STF, no sentido da realização de interrupção de gestação de anencéfalo, ou seja, feto sem cérebro. Essa decisão trouxe à tona questões jurídicas, morais, sociais e de outras ordens.

Para Diniz (2014, p. 102), a problemática do assunto surgiu:

Quando o legislador de 1940 editou o Código Penal, manteve a incriminação do aborto, mas segundo a "Exposição de Motivos", atendendo a razões de ordem social e individual, que o legislador penal não pode deixar de atender, introduziu o art. 128, tornando lícito o aborto praticado por médico habilita- 
do, em caso de aborto necessário ou em caso de prenhez resultante de estupro. Ora, é claro que, se o legislador de 1940 regulou hipótese extrema de morte de feto saudável concebido por estupro, procurava-se preservar a saúde psíquica da mulher, e, com muito mais razão, teria contemplado expressamente o aborto eugênico, caso a medicina da época possibilitasse antever as dificuldades advindas com o parto.

Cabe lembrar que o aborto é produto das práticas realizadas no abortamento, mas teve seu significado ligado ao uso comum e ao tipo penal. Conforme Alves (1999, p. 78):

O aborto pode ser estudado a partir de vários aspectos, mas é preciso analisá-lo enquanto conduta criminalizada que apresenta seu conceito primeiramente na Medicina. Desse locus, derivam-se as consequências jurídicas, religiosas e éticas, sendo que as primeiras variam entre países e culturas distintas. Assim, o aborto é a interrupção da gestação com a morte do feto acompanhada ou não da expulsão do produto da concepção do útero materno. A gravidez pode ser interrompida e o feto permanecer no claustro materno. Outras vezes, há expulsão do produto da concepção antes de sua viabilidade no mundo exterior. O feto, neste caso, é incapaz de sobrevida extra-uterina. Para a configuração do crime de aborto não é suficiente a simples interrupção da gestação, com a expulsão do feto, pois este pode ser expulso em condições de sobrevida e, em seguida, ser morto por outra ação punível. A morte do feto é pressuposto essencial para a configuração do aborto. Se, em decorrência da ação abortiva praticada pelo sujeito ativo, a gravidez é interrompida, mas o feto sobrevive, haverá tentativa de aborto.

Por esse conceito pode-se entender como o Código Penal trata essa conduta tipificada, sendo praticada por mulheres que não desejam levar a gravidez adiante (ALEGRETTI, 2005, p. 90).

O aborto hoje é um dos assuntos mais polêmicos que a Bioética abriga, envolvendo conceitos de vida, morte e religião. Esse tema é bastante controvertido em razão das pesquisas médicas efetuadas nessa área. A sua prática por pessoas que não apresentam habilidade profissional para fazer o aborto pode causar graves lesões à mulher, inclusive levando à sua morte. $\mathrm{O}$ aborto, por ser punido criminalmente, exceto nos casos em que a lei prevê excludentes de ilicitude, leva mulheres a realizá-lo de forma precária, em ambiente doméstico ou em clínicas clandestinas, para furtarem-se da punição criminal (ALEGRETTI, 2005, p. 91).

De acordo com o ordenamento jurídico penal, considera-se aborto o provocado pela gestante, ou provocado por terceiro com o seu consentimento (art. 124 do CP), provocado por terceiro, sem o consentimento da gestante (art. 125 do CP) ou o aborto provocado com o seu consentimento (art. 126 do CP) e nas formas qualificadas do artigo 127 do mesmo diploma legal todas essas práticas serão penalmente puníveis. Já os casos previstos no ordenamento jurídico (art.128 do CP) que não constituem ato ilícito são:

I - em caso de perigo, quando não há outro meio de salvar a vida da gestante; II - quando a gravidez é resultante de estupro e o aborto é precedido de consentimento da gestante, ou, se incapaz, de seu representante legal (ALEGRETTI, 2005, p. 91). 
Nesse momento, devem ser relevados dois aspectos importantes sobre esse assunto:

a) o direito brasileiro considera a gravidez um mero fato, que tem limites fisiológicos - a concepção e o início do parto. Há pouca ou nenhuma preocupação com a higidez psicológica da gestante, ou, mesmo, do embrião, como futura pessoa. A angústia pela deformação do próprio corpo, a preocupação se a criança vai nascer sadia, a afetividade, a certeza das deformações diagnosticadas intra-uterinamente, a incerteza sobre que tipo de vida futura a criança vai ter são questões que passam ao largo da abordagem jurídico penal ortodoxa. Fêmeas irracionais parem sem essas preocupações e o tratamento legal visível parece não fazer diferença entre elas e as racionais [...]

b) o bem jurídico tutelado, no caso do aborto, é a vida ou o direito à vida? resposta a essa pergunta deve ser precedida de profunda reflexão. A lei pátria não protege a vida, em seu valor intrínseco ou sagrado, mas o direito ao feto de viver e de continuar vivendo. O tratamento legal indica que o embrião é um sujeito de direito, pois... tem vida própria e recebe tratamento autônomo da ordem jurídica, além de que a lei põe a salvo, desde a concepção, os direitos do nascituro. A discussão é importante, à medida em que alcança o cerne do positivismo jurídico: quem concorda que o embrião é sujeito de direito e, portanto, seus interesses devem ser protegidos adotará o projeto positivista, que não admite a imbricação do direito com a moral e com a política e cujo primado é a lei; quem concorda com a proteção do feto porque a vida é inviolável e tem valor intrínseco e sagrado orientar-se sobre princípios e concorda, via de regra, que o direito é valor social e, portanto, aceita a intervenção direito/moral e direito/ política (ALEGRETTI, 2005, p. 93-94).

Sob essas condições, a mulher na sua gestação passa por diversas modificações físicas, psíquicas e hormonais. As alterações iniciam-se com a gestação, tornando-se mais agudas no final desse período. Assim, nos casos em que o feto apresente anomalias ou que impossibilite a vida, o abortamento deve ser realizado no início da gestação, ou melhor, nos casos em que a mulher optar pelo abortamento, para que o corpo e a mente possam se recuperar mais facilmente do que quando a intervenção é feita em período tardio. Acredita-se que era essa a "intenção" do legislador em seu artigo 128 (ALEGRETTI, 2005, p. 94).

O Código Civil diz que a personalidade jurídica do indivíduo começa a partir do nascimento dele com vida, mas a lei põe a salvo os direitos do nascituro. Dessa discrepância doutrinária para discutir quando começa a personalidade do ser humano surgem duas teorias:

A teoria Natalista teve sua origem na doutrina Romana, que não considerava o nascituro como pessoa humana. Para essa teoria, o feto adquire personalidade após o nascimento, e o subordina a três condições essenciais: nascimento, vida e a vitalidade (MUTUO; NARLOCH, 2005).

Segundo Reinaldo Pereira e Silva (2002, p. 106):

A teoria da natalidade é expressão de certa doutrina romana segundo a qual o concepto, nas entranhas maternas, não possui individualidade alguma, sendo apenas uma parte da mulher [...]. Esta teoria, apesar de rechaçada pelas descobertas no campo da embriologia humana, ainda é culturalmente muito influente. 
Ela é amparada por diversos juristas como Pontes de Miranda, Caio Mário da Silva Pereira e Silvio Venosa, e tal teoria, segundo César Fíuza, é aquela em que: “[...] o nascituro só adquire personalidade após o nascimento com vida" (FIÚZA, 2004, p. 117). Silvio Venosa (2005, p. 374) expõe que o nascituro é um sujeito com uma expectativa de direitos. Para ele, apenas "[...] há a mera possibilidade ou simples esperanças de se adquirir um direito". Essa teoria não considera o nascituro como pessoa, mas sim uma mera ficção jurídica.

De acordo com o artigo $2^{\circ}$. do CC, "A personalidade civil da pessoa começa do nascimento com vida; mas a lei põe a salvo, desde a concepção, os direitos do nascituro". Fiúza (2004, p. 114) afirma:

\begin{abstract}
O nascituro não tem direitos propriamente dito. Aquilo a que o próprio legislador denomina "direitos do nascituro" não são direitos subjetivos. São, na verdade, direitos objetivos, isto é, regras impostas pelo legislador para proteger um ser que tem a potencialidade de ser pessoa e que, por já existir pode ter resguardados eventuais direitos que virá a adquirir ao nascer.
\end{abstract}

A segunda teoria, chamada de Concepcionista, diverge da natalista para explicar o início da personalidade do feto. Ancorada no direito francês e tendo seguidores como Teixeira de Freitas e Clóvis Bevilacqua, essa teoria postula que desde o momento da concepção o nascituro é portador de personalidade, e por isso é considerado um ser humano e, dessa forma, um sujeito de direitos (GONÇALVES, 2008, p. 80).

Aliás, essa teoria enquanto fundamento aparece em decisões dos Tribunais Estaduais e do Superior Tribunal de Justiça como se verifica do Recurso Especial n. 1.415.727:

DIREITO CIVIL. ACIDENTE AUTOMOBILÍSTICO. ABORTO. AÇÃO DE COBRANÇA. SEGURO OBRIGATÓRIO. DPVAT. PROCEDÊNCIA DO PEDIDO. ENQUADRAMENTO JURÍDICO DO NASCITURO. ART. $2^{\circ}$. DO CÓDIGO CIVIL DE 2002. EXEGESE SISTEMÁTICA. ORDENAMENTO JURÍDICO QUE ACENTUA A CONDIÇÃO DE PESSOA DO NASCITURO. VIDA INTRAUTERINA. PERECIMENTO. INDENIZAÇÃO DEVIDA. ART. $3^{\circ}$., INCISO I, DA LEI N. 6.194/1974. INCIDÊNCIA.

$[\ldots]$

Hoje, mesmo que se adote qualquer das outras duas teorias restritivas, há de se reconhecer a titularidade de direitos da personalidade ao nascituro, dos quais o direito à vida é o mais importante. Garantir ao nascituro expectativas de direitos, ou mesmo direitos condicionados ao nascimento, só faz sentido se lhe for garantido também o direito de nascer, o direito à vida, que é direito pressuposto a todos os demais. 5. Portanto, é procedente o pedido de indenização referente ao seguro DPVAT, com base no que dispõe o art. $3^{\circ}$. da Lei n. 6.194/1974. Se o preceito legal garante indenização por morte, o aborto causado pelo acidente subsume-se à perfeição ao comando normativo, haja vista que outra coisa não ocorreu, senão a morte do nascituro, ou o perecimento de uma vida intrauterina (Recurso especial provido. Resp no ${ }^{\circ}$ 1.415.727 -SC (2013/0360491-3. Rel. Ministro Lusi Felipe Salomão. DJe 29/09/2014).

Os seguidores dessa corrente atribuem direitos ao nascituro, desde o momento da concepção, portanto deve-se reconhecê-lo também como pessoa - tendo em vista que os 
direitos são atributos exclusivamente das pessoas. Sendo assim, essa corrente entende que o nascituro tem personalidade jurídica sendo sujeito de direitos e, portanto, é pessoa (SEMIÃO, 2001, p. 35).

Carlos Roberto Gonçalves, (2004, p. 81), tratando da teoria da personalidade, destaca que não há meia personalidade ou personalidade parcial. Mede-se ou se qualifica a capacidade, não a personalidade. Esta é integral ou não existe. Pode-se ser mais ou menos capaz, mas não se pode ser mais ou menos pessoa. Portanto, para os adeptos dessa teoria, todo ser que apresenta sinais característicos de ser humano adquire essa capacidade, são pessoas de existência real. Segundo o autor Elimar Szaniawski (1993, p. 64), as pessoas chamadas de pessoas "por nascer" possuem personalidade e capacidade desde a concepção.

Devemos considerar em que medida a hipótese que defende o debate sobre o aborto é um debate sobre valores intrínsecos e não sobre direitos ou interesses do feto. A contradição principal está nesta que é uma espécie de brecha na lei: em certos casos, como em estupros ou em situações de fetos anencéfalos, alguns juízes já permitiram o aborto.

Ao legitimar certas práticas abortivas, os tribunais caem em contradição e se afastam da moral cristã, visto que esta não aceita o aborto em hipótese alguma. O embasamento dos juristas conservadores acaba por se tornar menos sólido, visto que a lei não se aplica a todo e qualquer caso de gestação. A crise surge na impossibilidade de ser decidido entre quem deve ser privilegiado pela lei: a mulher ou o feto, sendo esse o grande conflito entre o direito e a moral. Em sua obra Domínio da Vida, Dworkin (2003, p. 11-12) expõe:

\footnotetext{
Enquanto o debate for colocado nesses termos polarizados, os dois lados não poderão raciocinar em conjunto, pois nada terão sobre o que raciocinar ou ser razoáveis. Um dos lados acredita que o feto humano já é um sujeito moral, uma criança não nascida, a partir do momento da concepção. O outro acredita que um feto recém-concebido não passa de um aglomerado de células sob o comando não de um cérebro, mas apenas de um código genético, e que nesse caso, é uma criança tanto quanto um ovo recém fertilizado é um frango. Nenhum dos lados é capaz de oferecer um argumento que o outro possa aceitar - não há nenhum fato biológico à espera do ser descoberto, nenhuma analogia moral esmagadora à espera de ser inventada que possa resolver o problema. Trata-se de uma questão de convicções inatas.
}

No Brasil, os serviços de aborto legal são unidades de referência no Sistema Único de Saúde (SUS) para o atendimento de mulheres nas situações descritas pela lei. Um serviço de saúde é reconhecido como uma unidade de referência para o aborto legal por meio de uma decisão do Ministério da Saúde (MS) (BRASIL, 2005).

Os serviços para o aborto legal no SUS foram projetados para cuidar de vítimas de estupro e mulheres em risco de morte, duas situações em que o CP não pune os médicos, nem as mulheres que praticam o aborto. Políticas do MS não restringem a assistência médica em casos de aborto para o setor público. No entanto, presume-se que o aborto será realizado em hospitais públicos devido ao modelo de atenção da equipe multiprofissional e devido à Portaria 1.508/2005, pelo Ministério da Saúde, que regulamenta a assistência para o aborto legal em SUS (BRASIL, 2005). 
O médico pode opor-se a um pedido de aborto. Ao alegar a objeção de consciência, o médico deve solicitar autorização para não cumprir a sua obrigação e a mulher deve ser atendida por outro médico. Orientações técnicas do Ministério da Saúde não reconhecem o direito à objeção de consciência, quando existe um risco de morte, quando não há outro médico ou quando a falta de atenção médica prejudica as mulheres, mas os casos recentes revelam a não adesão ao critério normativo (DINIZ, 2005).

No outro extremo, a objeção de consciência é entendida como um direito individual não só de médicos, mas de todas as pessoas envolvidas direta ou indiretamente nos cuidados de saúde. Toda vez que a integridade moral de uma delas for desafiada pela exigência de uma paciente. No caso de aborto legal, a tese da integridade garante que os médicos, psicólogos, assistentes sociais, enfermeiros, farmacêuticos ou pessoal administrativo, cada um em seu próprio papel, tenham o direito de recusar assistência ou prestação de serviços devido a motivações pessoais. Essa tese assume uma sobreposição entre os papéis do profissional de saúde e um ser humano moral; antes de ser um médico no serviço de saúde do Estado, a pessoa é membro de uma comunidade moral que determina a sua consciência, incluindo os limites entre o que é certo e errado (BRASIL, 2005).

O novo CEM Brasileiro (2010, p. 4) reconhece o direito à objeção de consciência, mas impõe restrições à sua prática: o médico não é obrigado a fornecer serviços que contradizem os ditames de sua consciência, exceto em caso de urgência ou de emergência ou quando a recusa pode prejudicar a saúde do paciente.

Portanto, fica garantido aos médicos e demais profissionais da saúde o direito legítimo de recusar a praticar atos contrários à sua moral, desde que isso não coloque em risco a vida de terceiro. Cabe ao médico, ainda, nas situações em que recusar a fazer o procedimento de aborto dar todas as informações para a paciente, esclarecendo todas as suas dúvidas, inclusive quanto ao dever do Estado em garantir que o método ocorra de forma segura para a gestante. Fica o médico obrigado a encaminhar a paciente para um local onde tenha um serviço habilitado e capacitado para realizar o aborto.

\section{CONSIDERAÇões FINAIS}

Sem dúvida, o exercício da objeção de consciência, especialmente na medicina, é uma questão altamente complexa, porque muitos interesses estão envolvidos em conflito. Em conclusão, objeção de consciência é um instrumento de grande valor democrático, na medida em que permite salvaguardar a integridade moral de uma pessoa e colaborar na construção de um pluralismo real.

No entanto, devem ser considerados os contextos, práticas e dinâmicas em cada caso. Conclui-se que o médico tem direito à objeção de consciência apenas quando não prejudica a saúde da mulher, quando é possível alocar imediatamente outro profissional de saúde para realizar o procedimento e quando essa objeção não causa atraso na prestação do serviço de saúde ou constrangimento para a paciente.

Sabe-se que, em vários países, já ocorreram mudanças em relação aos direitos reprodutivos, restando o Brasil como um dos poucos países ocidentais onde não se autoriza a 
prática do aborto. Nos países em que essa prática é autorizada, a objeção de consciência médica diz respeito à recusa do médico em realizar esse procedimento, motivado por parâmetros éticos, morais ou religiosos.

Sobre essa temática, conclui-se que cada Estado democrático deve estar comprometido com a criação de espaços para a convivência de várias crenças. Existem barreiras significativas e assimetrias na área de reprodução e sexualidade entre os próprios profissionais e entre os profissionais e as mulheres.

Finalmente, cabe citar a responsabilidade criminal do médico, uma vez que o seu exercício pode ter consequências sobre os direitos jurídicos protegidos pelo direito penal, como a vida e a integridade pessoal e liberdade individual. A discussão assume que não é possível aplicar uma ação de responsabilidade inteiramente objetiva, mas deve haver um julgamento de ponderação entre os vários direitos e deveres de todos os envolvidos no ato médico e a relação médico-paciente sob observância de disposições constitucionais, bem como, o sistema penal substancial e a ética médica.

\section{REFERÊNCIAS}

ALEGRETTI, Carlos Artidorio. Revisão Crítica do Conceito do Crime de Aborto: a busca de um consenso possível. Revista Jurídica: Órgão Nacional de Doutrina, Leg. e Crítica Judiciária. São Paulo, v. 3, n. 334, ago. 2005.

ALVES, Ivanildo Ferreira. Crimes contra a vida. Belém: UNAMA, 1999.

BELLO P. Derecho penal, objeción de conciencia y hecho religioso. Disponível em: http://www.ical.es/locus/51/articulos/derecho_penal.pdf. Acesso em: 30 jun. 2019.

BONILLA JJ. De nuevo sobre la objeción de conciencia sanitária [2011]. Disponivel em: $<$ http://andoc.es/actas.pdf $>$. Acesso em: 30 jun. 2019.

BRASIL. Constituição (1988). Constituição da República Federativa do Brasil. In: Vade Mecum, 3. ed. São Paulo: Saraiva, 2007.

BRASIL, 2010. CÓDIGO DE ÉTICA MÉDICA. Resolução Conselho Federal de Medicina $\mathrm{n}^{0}$. 1.931, de 17 de setembro de 2009. Disponível em: < https://portal.cfm.org. br/images/stories/biblioteca/codigo\%20de\%20etica\%20medica.pdf $>$ Acesso em: 20 out. 2020.

DINIZ, Maria Helena. O estado atual do biodireito, 9. ed. São Paulo: Saraiva, 2014.

DIREITO, Carlos A. M. Do erro médico. In: Doutrina. Brasília: Superior Tribunal de Justiça, 2005. 
DWORKIN, Ronald. Domínio da Vida, Aborto, eutanásia e liberdades individuais. São Paulo: Martins Fontes, 2003.

FALCÃO, Rafael de Lucena. Direito à vida: a importância do marco inicial e a incoerência que seria o direito ao aborto no ordenamento jurídico. Disponível em: www. egov.ufsc.br. Acesso em: 5 mai. 2019.

FIÚZA, César. Direito Civil. Curso completo, 8. ed. rev., atual., ampla. Belo horizonte: Del Rey, 2004.

GARCÍA FERNÁNDEZ D. Hasta la objeción de conciencia sirve para proteger al embrión humano. Revista el mundo del abogado, México, 104, 2007.

GARCIA, Ibere A. O risco permitido como critério de imputação do erro médico. In: Revista dos Tribunais: 100 anos. Doutrinas Essenciais: Direito Penal, v. III. São Paulo: Revista dos Tribunais, 2011.

GARCIA, María Cebría. Objeciones de conciencia a intervenciones médicas: doctrina y jurisprudencia. Thomson Aranzadi: Pamplona, 2005.

GÓMEZ M. La responsabilidad penal del médico. Valencia: Tirant lo Blanch, 2003.

GONÇALVES, Carlos Roberto. Direito Civil Brasileiro, 2. ed. São Paulo: Saraiva, 2008.

Grande Enciclopédia Barsa. São Paulo: Barsa Planeta Internacional LTDA., v. 14, 2005.

LEE, G. M., SOTELO, G.; CASA, O. La objeción de conciencia en la práctica del médico. Disponível em: http://www.ejournal.unam.mx/rfm/no49-3/RFM49310.pdf. Acesso em: 30 jun. 2019.

MENDES, Gilmar Ferreira; BRANCO, Paulo Gustavo Gonet. Curso de direito constitucional, 7. ed. São Paulo: Saraiva, 2012.

MUÑOZ B. La objeción de conciencia. Disponível em: http://www.bioeticacs.org/iceb/ seleccion_temas/objecionConciencia/La_Objecion_de_Conciencia.pdf. Acesso em: 30 jun. 2019.

MUTUO, Eliza; NARLOCH, Leandro. Vida: o primeiro instante. Revista Super Interessante, n. 219, nov. 2005. Disponível em: http://super.abril.com.br/ciencia/vida-o-primeiro-instante. Acesso em: 20 abr. 2019.

PACHECO. Newton. O erro médico: responsabilidade penal. Porto Alegre: Livraria do Advogado, 1991. 
PELAYO Á. La objeción de conciencia sanitaria. In: BARRANCO, M. C., GARRIDO, M. I. Libertad ideológica y objeción de conciencia. Pluralismo y valores en derecho y educación. Madrid: Dykinson, 2011.

PLATÃO. A imortalidade da alma. Disponível em: $<$ http://www.dominiopublico.gov.br/ pesquisa/ResultadoPesquisaObraForm.do $>$. Acesso em: 10 jun. 2019.

SEMIÃO, Sérgio Abdalla. Os direitos do nascituro: aspectos cíveis e criminais do biodireito, 2. ed. rev. atual. e ampl. Belo Horizonte: Del Rey, 2001.

SILVA, José Afonso da. Curso de direito constitucional positivo, 30. ed. São Paulo: Malheiros, 2008.

SILVA, Reinaldo Pereira; LAPA, Fernanda Brandão. Bioética e Direitos Humanos. Florianópolis: $\mathrm{OAB} / \mathrm{SC}$ Editora, 2002.

STJ. RECURSO ESPECIAL: REsp 1.415.727 - SC. Rel. Ministro Lusi Felipe Salomão. DJe 29/09/2014. Disponível em: <https://www.stj.jus.br/sites/portalp/Paginas/Comunicacao/Noticias/Jurisprudencia-reconhece-direitos-e-limites-a-protecao-juridica-do-nascituro.aspx> Acesso em: 20 out. 2020.

SZANIAWSKI, Elimar. Direitos de Personalidade e sua tutela, 2. ed. São Paulo: Revista dos Tribunais, 1993.

TAVARES, André Ramos. Curso de direito constitucional, 7. ed. São Paulo: Editora Saraiva, 2009.

VENOSA, Silvio de Salvo. Direito civil: parte geral, 7. ed. São Paulo: Atlas, 2005.

\section{Regiane NisTLer}

Doutoranda em Direito pela Universidade Estácio de Sá (UNESA), campus do Rio de Janeiro (RJ). Mestre em Direito, Democracia e Sustentabilidade pela Faculdade Meridional (IMED), campus de Passo Fundo (RS). E-mail: regianenistler@outlook.com.

\section{Marco Augusto Ghisi Machado}

Mestre em Direito pela Universidade do Vale do Itajaí (UNIVALI), campus de Itajaí (SC). E-mail: marcoagmachado@hotmail.com.

Submetido em: $18-4-2020$

Aceito em: 5-11-2020 